\title{
Optimization of Coral Video Transect Technique for Coral Reef Survey: Comparison with Intercept Transect Technique
}

\author{
Mohd Safuan1, Wee Hin Boo1, Hii Yi Siang2, Liew Hock Chark ${ }^{3}$, Zainudin Bachok ${ }^{3 *}$ \\ ${ }^{1}$ Institute of Oceanography and Environment, Universiti Malaysia Terengganu, Kuala Terengganu, Malaysia \\ ${ }^{2}$ School of Fisheries and Aquaculture Sciences, Universiti Malaysia Terengganu, Kuala Terengganu, Malaysia \\ ${ }^{3}$ School of Marine Science and Environment, Universiti Malaysia Terengganu, Kuala Terengganu, Malaysia \\ Email: zainudinb@umt.edu.my
}

Received 25 July 2015; accepted 4 October 2015; published 7 October 2015

Copyright (C) 2015 by authors and Scientific Research Publishing Inc.

This work is licensed under the Creative Commons Attribution International License (CC BY). http://creativecommons.org/licenses/by/4.0/

(c) (i) Open Access

\begin{abstract}
Variety in video sampling protocol for coral reef survey worldwide has prompted this study to create an optimized protocol for Coral Video Transect (CVT) technique for coral reef survey in Malaysia. The effect of different vertical distance of the camera above the substrate during video recording, number of frames and points analyzed as well as time spent during field and analysis were examined to determine an optimal protocol for CVT technique at different coral reef conditions in Malaysia's water. Video recording taken at $0.5 \mathrm{~m}$ camera distance was selected as optimize vertical distance above the substrate as it can identify more benthic categories than $1.0 \mathrm{~m}$ with lesser time taken as well as frames extracted than $0.2 \mathrm{~m}$. Respectively, $80 \%$ of total frames extracted from $20 \mathrm{~m}$ transect and analyzed with 50 points per frames were chosen as an optimized sample size for its ability to precisely estimate percent cover and accurately identify benthic categories. This optimized protocol was then compared with Line Intercept Transect (LIT) method. No clear difference in estimating percentage cover of major benthic categories between CVT and LIT method, but CVT recorded a significantly higher number of benthic categories with lesser time spent during field survey as compared to LIT method. This implied that the optimize CVT method can precisely estimate percent cover and accurately identify benthic categories in coral communities and are thus more suitable for scientific research and management purposes than LIT method. Other advantages of using this technique are by providing a permanent data that can be reassessed later on, lesser field time and wider survey area. Overall, this study showed that CVT technique is an acceptable alternative method of coral reef survey in Malaysia.
\end{abstract}

${ }^{*}$ Corresponding author.

How to cite this paper: Safuan, M., Boo, W.H., Siang, H.Y., Chark, L.H. and Bachok, Z. (2015) Optimization of Coral Video Transect Technique for Coral Reef Survey: Comparison with Intercept Transect Technique. Open Journal of Marine Science, 5, 379-397. http://dx.doi.org/10.4236/ojms.2015.54031 


\section{Keywords}

\section{Coral Reef Survey, Coral Video Transect, Optimize Protocol}

\section{Introduction}

Coral reefs are among the most productive ecosystems, providing habitat and refuge for diverse marine species [1]. However, coral reefs are under serious threat as a result of anthropogenic pressures and global climate change. Climate change has caused the coral bleaching [2], whereas, other pressures such as hurricane damage and disease in coral also recorded as threats to coral [3]. A variety of human disturbances to coral reef such as overfishing, destructive fishing, recreational activities and coastal development have also led to the declining of coral [2] [4]-[6]. Therefore, variety survey methods have been developed to provide the information about coral reef status and their conditions.

Various methods have been developed to assess coral reef status [7] [8]. Basically, field transect is the most widely used methods as it is easy and simple to conduct [9] as well as less costly [10]. Line Intercept Transect (LIT) method is one of the most common transect methods, which measures the length of corals that intercept a transect line and assess the percentage cover of the corals by their relative lengths [7]. However, this in-situ visual method requires long diving time, tends to miss small species and must be conducted by an expert in coral identification [11]. In a meantime, the data collected cannot be verify or reassess unless the surveys are repeated [12].

The use of digital underwater camera for coral reef surveys either by photographic or video is becoming popular [13]. The video technique is more likely to be used as video recording is easier and less time consuming than still photography [14]. Experienced divers can collect data through videotaping, whereas marine biologists work on the video records for data analysis, thus greatly reduced field expense and time [9]. It also offers a permanent record that can be archived and reviewed for data verification or comparison later on [3] [12] [15]. It also enables the researcher to cover a far greater area per unit sampling effort [9] [14].

Presently, the most common methods that have been used to conduct coral reef survey in Malaysia are the LIT method [7] or the Point Intercept Transect (PIT) method used by Reef Check [16]. Most recently, video sampling was introduced [12] and has been used in several surveys in East Coast of Peninsular Malaysia. However, no standard protocol for field and data analysis of video recording has been documented in Malaysia.

Coral monitoring methods also vary regionally due to variation in the composition of coral reef community, oceanographic characteristics, and economic constraints [17]. Many countries have developed their own video sampling protocols to meet the requirement of their reef system [14] [15] [17]-[19]. Since there is no standard protocol for video sampling in Malaysia, the video technique called Coral Video Transect (CVT) method [12] was examined by creating an optimal protocol for field survey and data analysis. Then, this optimize protocol was compared with conventional method called Line Intercept Transect (LIT) method so as to identify the best approach to document coral reef status in Malaysia.

\section{Materials and Methods}

\subsection{Study Sites}

This study was undertaken at two islands namely Bidong Island and Redang Island, located in Kuala Terengga$\mathrm{nu}$, Malaysia. Bidong Island, located at $5^{\circ} 37^{\prime} 7.60 " \mathrm{~N}$ latitude and $103^{\circ} 3^{\prime} 47.84^{\prime \prime E}$ longitude, is a well-known island with the history of Vietnamese refugees. The tropical island of Redang Island ( $\left.5^{\circ} 46^{\prime} 26.94 " \mathrm{~N}, 103^{\circ} 0^{\prime} 35.00^{\prime \prime} \mathrm{E}\right)$ located around one hour from Kuala Terengganu, Malaysia is the largest island between 13 Marine Parks in Terengganu.

\subsection{Coral Video Transect Optimization}

Nine sampling sites were chosen based on different coral reef conditions (good, moderate and poor [20]) to conduct CVT technique with a different vertical distance of the camera above the substrate $(1.0 \mathrm{~m}, 0.5 \mathrm{~m}$ and 0.2 $\mathrm{m}$ ) as listed in Table 1 and showed in Figure 1. A $20 \mathrm{~m}$ transect line was laid along the reef floor by following the reef contour. An underwater camera with underwater housing from Panasonic (LUMIX FT4 with LUMIX 
$40 \mathrm{~m}$ Marine Case with 28 - $128 \mathrm{~mm}$ lens) to obtain video clips of the $20 \mathrm{~m}$ transect at each study site. A wide angle with a ratio of 16:4 and $1920 \times 1080$ resolutions with underwater mode were adjusted to get a high quality of fully high definition (HD) video. The use of high video resolution was recommended [9] [12] [15]. The first shoot was taken by facing the camera perpendicular down at $1.0 \mathrm{~m}$ above the substrate along the transect line and entire $20 \mathrm{~m}$ transect was recorded at a speed of relatively $5 \mathrm{~m}$ per minute. The camera was maintained perpendicular to the substratum by using a reference bar to minimize the parallax error and to keep it in focus until entire $20 \mathrm{~m}$ transect was fully recorded. These procedures were then repeated for different camera distance from substrate at $0.5 \mathrm{~m}$ and $0.2 \mathrm{~m}$. Time spent to completely survey $20 \mathrm{~m}$ transect by each different camera distance from the substrate during field and data analysis was also recorded.

\subsection{Comparison between CVT and LIT Method}

A comparison was made between the optimized CVT with LIT method along $20 \mathrm{~m} \times 4$ segments transect. Six sampling sites were chosen randomly at two different depths $(3 \mathrm{~m}$ and $10 \mathrm{~m})$ as shown in Table 2 and Figure 1. The sampling begun by overlaying a $100 \mathrm{~m}$ transect at the sampling area. The first data collection was done using LIT method along $20 \mathrm{~m} \times 4$ segment transects as outlined in [12]. Data were recorded by moving slowly along the transect line and by measuring all the benthic categories intercepted beneath the tape [7]. Then, the CVT method was conducted along the similar transect line. Video recording was taken by swimming slowly along the transect line by facing the camera perpendicular above the substrate using an optimize camera distance from the substrate. Video shooting was done as close as possible to transect tape without recording the tape to ensure the CVT and LIT methods sampled the same benthic community. The time consumed during field survey and data analysis was also recorded between the optimal protocol of CVT and LIT method. Time taken for transect set up was not considered as both used a similar transect line.

\subsection{Determination of Percentage Benthic Cover and Number of Benthic Categories Identified}

The percentage major benthic cover (coral, algae, other invertebrates and dead coral) and number of benthic categories (coral genera, coral growth form and others) were calculated from different camera distance from the substrate (1.0 m, $0.5 \mathrm{~m}$ and $0.2 \mathrm{~m}$ ), number of frames (20\%, 30\%, 50\%, 80\% and $100 \%$ frames extracted from $20 \mathrm{~m}$ transect) and number of points analyzed (5, 10, 20, 30, 50, 75, 100, 150, and 300 points per frame). The percentage cover was automatically calculated by Coral Point Count with Excel Extension (CPCe) software [21]. Number of benthic categories identified was counted from the results generated by the CPCe software. A copied data from LIT method was calculated to determine the percentage cover for each major benthic category identified. The length for each benthic category measured was calculated and percentage cover of each of them was determined by following [7]. Number of benthic categories identified was count directly from the data recorded.

Corals and other benthic categories exist around the sampling sites were photographed and identified to the lowest taxonomic level to aid in identification later. Identification of coral genera was done by following

Table 1. Selected sites according to coral reef condition (good, moderate and poor) to determine benthic cover at different camera distance from the substrate (20 m transect line)

\begin{tabular}{cccc}
\hline Coral Condition & Good $(\mathbf{2 5 0} \mathbf{5 0}$ & Moderate $\mathbf{( 2 5 \%} \mathbf{- 5 0} \%)$ & Poor (<25\%) \\
\hline \multirow{3}{*}{ Sampling Site } & Ekor Tebu (T1) & Ekor Tebu (T4) & Chagar Hutang (T7) \\
& Batu Bara (T2) & Chagar Hutang (T5) & Terumbu Kili (T8) \\
& Karah Island (T3) & Mak Simpan (T6) & Terumbu Kili (T9) \\
\hline
\end{tabular}

Table 2. Selected sites for the determination of benthic cover using CVT and LIT methods at two different depths of $3 \mathrm{~m}$ and $10 \mathrm{~m}(20 \mathrm{~m} \times 4$ segments transect line $)$.

\begin{tabular}{ccc}
\hline Depth & $\mathbf{3} \mathbf{~ m}$ & $\mathbf{1 0} \mathbf{~ m}$ \\
& Ekor Tebu (T1) Batu Bulan (T4) & Batu Bara (T5) \\
Sampling Site & Terumbu Kili (T2) & Terumbu Kili (T6) \\
\hline
\end{tabular}



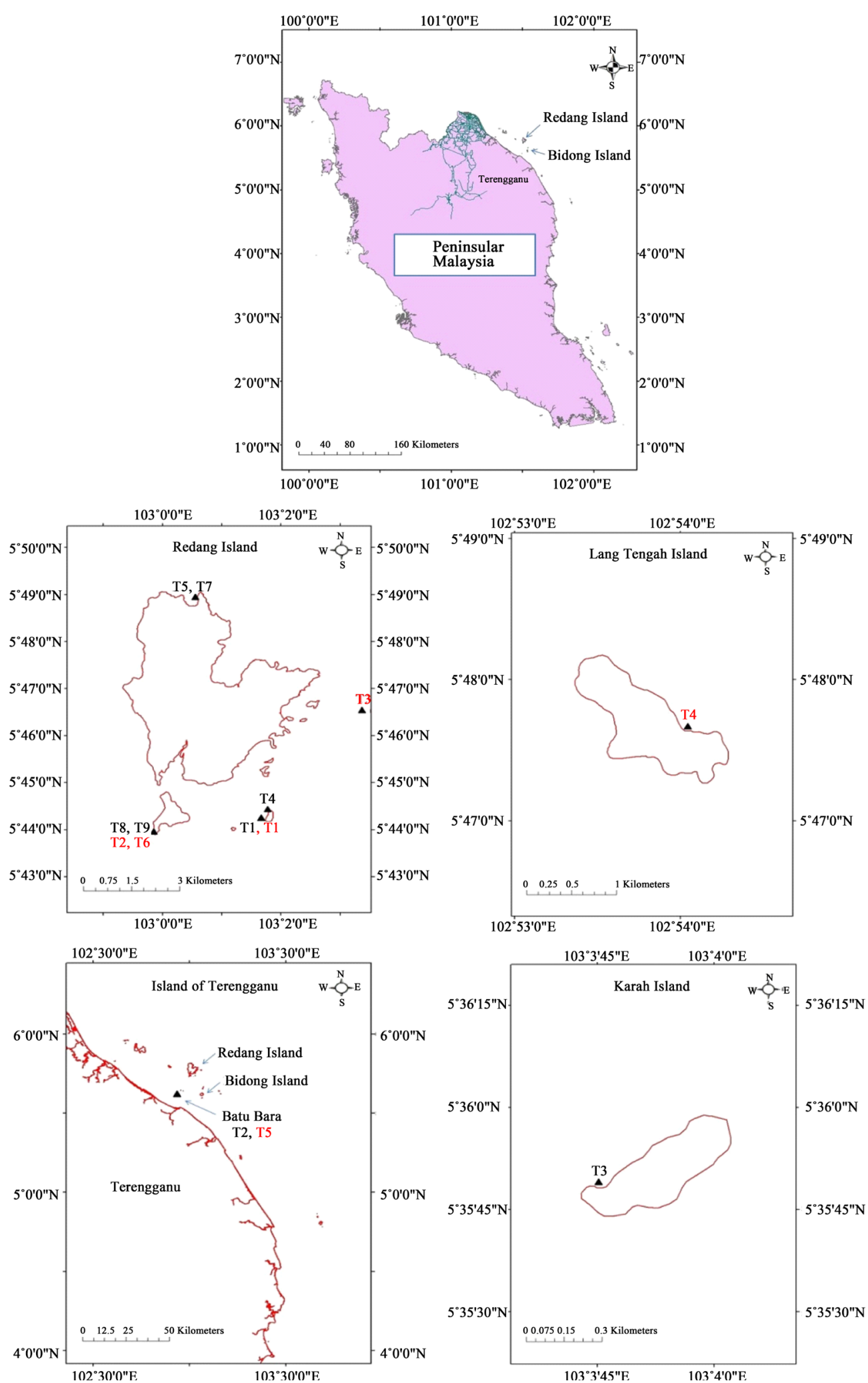

Figure 1. Map of Peninsular Malaysia shows location the state of Terengganu and the sampling location at Bidong and Redang Island. T1 until T9 stations (black) indicated the selected sites according to coral reef condition (good, moderate and poor) to determine benthic cover at different camera distance from substrate whereas T1 until T6 (red) indicated as sites for conducting CVT and LIT method. 
[22]-[24], whereas the other categories were identified by following [7] [18] [25].

\subsection{Data Analysis}

The one-way multivariate analysis of variance (one-way MANOVA) was used to determine whether the time spent during field survey and data analysis as well as percent cover and number of benthic categories identified either significantly dependent or not on the different vertical camera distance being used during video recording by CVT method at different reef conditions.

The percentage cover of major benthic categories obtained from a different number of frames extracted (20\%, $30 \%, 50 \%, 80 \%$ and $100 \%$ frames of $20 \mathrm{~m}$ transect) and points analyzed (300,150,100, 75, 50, 30, 20, 10, and 5 points) was further subjected to precision value. The resolving power of various sample sizes can be compared by examining the relationship between the precision value $(s / \sqrt{n})$ and sample size $(s=$ standard deviation, $n=$ sample size) [26]. The $n$ value is equal to the number of frames multiply with the number of points per frame. As the precision value decreases, the precision of the data will increase [8], therefore sample size with a lowest precision value is the sample size with highest ability to precisely estimate the percent cover of benthic categories. Besides that, the accuracy to identify benthic categories was also determined. Sample size with the ability to identify benthic categories as close to true value was selected as an optimize sample size. In this study, maximum number of frames (100\%) and points (300 points) were acted as a baseline value of precision and true value for a mean total number of benthic categories identify. The point at which precision or mean number of benthic categories is no longer increases, or increases slowly, as well as close to the baseline value is a good first approximation of the sample size required to analyze video footage.

Differences in percentage cover, number of benthic categories and time taken to complete the survey from optimized CVT and LIT method were analyzed by the Student t-test by following [9]. Difference with $\mathrm{p}<0.05$ was considered significant. All percent data were arcsine transform prior to statistical test [27].

\section{Result and Discussion}

\subsection{Pros and Cons of Different Camera Distance from Substrate}

Generally, area cover increase with the increment of the vertical distance between camera and substrate as listed in Table 3. In contrast, previous studies found that video recorded at $0.5 \mathrm{~m}$ above the substrate filmed 0.075 $\mathrm{m}^{2} /$ frame area [17], follow by $0.4 \mathrm{~m}$ camera distance which recorded $0.15 \mathrm{~m}^{2} /$ frame [9] and $0.3 \mathrm{~m}$ to $0.35 \mathrm{~m}$ camera distance which covering $0.165 \mathrm{~m}^{2} /$ frame [28]. These differences might indicate from different types of camera lens used during video recording. For example, video recording by different types of camera at a similar camera distance from substrate yield different area cover $\left(\mathrm{ROV}=0.26 \mathrm{~m}^{2} /\right.$ frame and SCUBA diver $=0.15 \mathrm{~m}^{2}$ ) [9]. As the video was recorded closer to the substrate, area cover decreased, but consequently increased the number of frames extracted as showed in Table 3. Previous studies also showed the number of frames increase as the vertical distance of camera above the substrate decrease (camera distance $=1.0 \mathrm{~m}$ frames $/ \mathrm{m}=1.16$ to 1.28 [29], , camera distance $=0.4 \mathrm{~m}$ frames $/ \mathrm{m}=2.4$ to 2.8 [3], camera distance $=0.3-0.35 \mathrm{~m}$ frames $/ \mathrm{m}=2.72$ [28]).Thus, video recording by different camera distance would yield different proportion of area cover as greater the camera distance from the substrate, more sample per unit area can be cover with fewer number of frames extracted.

Time consuming during (a) field survey F $(3,8)=8.16$ ( $\mathrm{p}<0.001)$ and (b) data analysis $\mathrm{F}(3,8)=23.26$ ( $\mathrm{p}<$ 0.001 ) were increased significantly as the camera becomes closer to the substrate as illustrated in Figure 2 . The CVT methods could be accomplished more quickly when the video was recorded at $1.0 \mathrm{~m}$ camera vertical distance than $0.5 \mathrm{~m}$ and $0.2 \mathrm{~m}$. Ability to record wider area during video recording will eventually speed up the

Table 3. Area covers $\left(\mathrm{m}^{2}\right)$ along the $20 \mathrm{~m}$ transect line recorded and the number of frames extracted from $20 \mathrm{~m}$ video recording at three different distances between camera and substrate $(1.0 \mathrm{~m}, 0.5 \mathrm{~m}$ and $0.2 \mathrm{~m})$. Value for number of frames was Mean \pm SD.

\begin{tabular}{ccc}
\hline Distance Between Camera and Substrate, $\mathbf{m}$ & Area Cover of Transect Recorded, $\mathbf{m}^{2}$ & Total Number of Frames Extracted $^{2}$ \\
1.0 & 12.5 & $33.11 \pm 2.37$ \\
0.5 & 6 & $56 \pm 5.29$ \\
0.2 & 2.5 & $92.56 \pm 3.47$ \\
\hline
\end{tabular}


survey. Closer the camera to substrate causes magnification of reef floor, which reduced area cover of video recording and consequently spent more time during field survey. Moreover, time consuming during data analysis was increased due to the increment of the number of frames extracted as the camera closer to the substrate. Therefore, sampling and analytical effort will increase when the video recording taken closer to the substrate.

The statistical test showed that percent cover of (a) C, (b) ALG, (c) OT and (d) DC were not significantly dependent on the different vertical camera distance being used during video recording by CVT method at different reef conditions $(p>0.05)$ as displayed in Figure 3. Comparison on the percentage cover of coral reef benthos

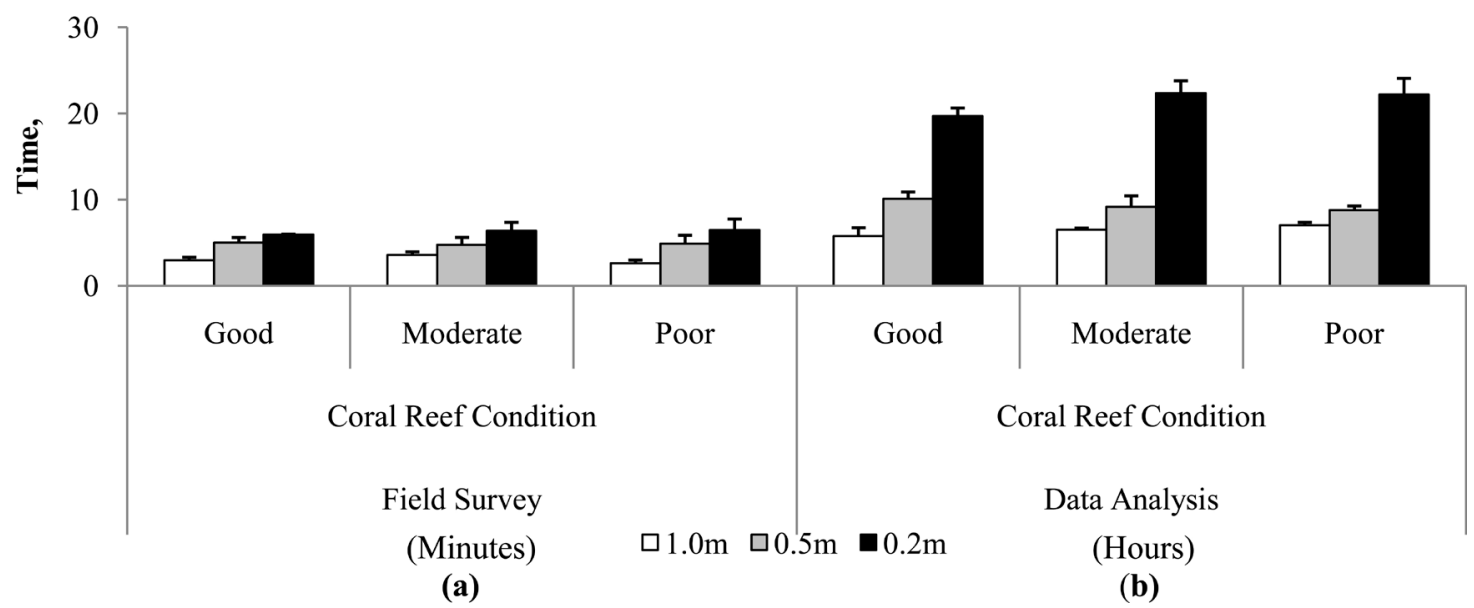

Figure 2. Comparison of time consuming among three different camera distance from the substrate $(1.0 \mathrm{~m}, 0.5 \mathrm{~m}$ and $0.2 \mathrm{~m})$ between (a) field survey (minutes) and (b) data analysis (hours) at good, moderate and poor coral reef condition at Bidong and Redang Island. Values are Mean $\pm \mathrm{SD}, \mathrm{n}=3$.
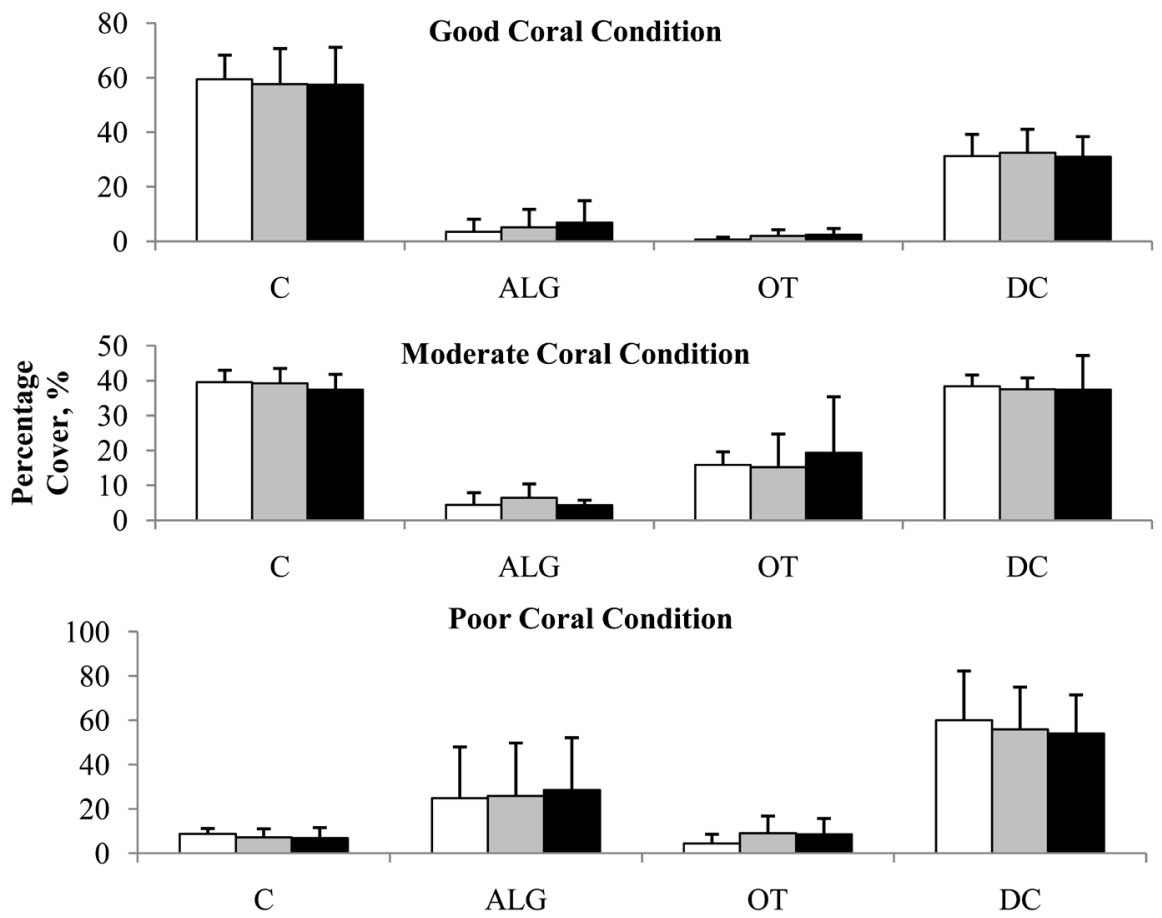

(a)

(b)

(c)

(d)

$\square 1.0 \mathrm{~m} \quad \square 0.5 \mathrm{~m} \quad \mathbf{\square} 0.2 \mathrm{~m}$

Figure 3. Comparison of percentage major benthic cover (\%) of (a) coral (C), (b) algae (ALG), (c) other invertebrates (OT) and (d) dead coral (DC) determine at a different camera distance from the substrate $(1.0 \mathrm{~m}, 0.5 \mathrm{~m}$ and $0.2 \mathrm{~m})$ at good, moderate and poor coral reef condition. Values are Mean $\pm \mathrm{SD}, \mathrm{n}=3$. 
between large and smaller spatial scale using video method at the Central of Great Barrier Reefs showed that there was no significant difference in the mean coral cover at different spatial scale [15]. Similarly, no clear difference was found in estimating percentage cover of coral species by ROV and SCUBA diver, although both recorded different area cover during video recording [9]. This indicates that, videos taken at a different vertical camera distance from the substrate might not influence the estimation of coral percentage cover.

Figure 4 showed the number of benthic categories identified recorded from different camera distance from substrate. The statistical test also showed the detection for number of benthic categories identified was not significantly dependent on different vertical camera distance used during video recording by CVT method at different reef conditions ( $\mathrm{p}>0.05$ ). $1.0 \mathrm{~m}$ camera distance recorded relatively the highest number of $(\mathrm{b})$ coral growth form as compared to $0.5 \mathrm{~m}$ and $0.2 \mathrm{~m}$ camera distance. More (a) coral genera and (c) other categories were detected when video shooting was done at $0.5 \mathrm{~m}$ and $0.2 \mathrm{~m}$ camera distance from the substrate as compared to $1.0 \mathrm{~m}$. More benthic categories are included when the camera distance from the substrate increase [8]. Nevertheless, greater the camera distance from the substrate can cause limitation in taxonomic resolution for video sampling when compare with LIT method, thus closer video recording to the substrate was recommended [15]. This indicates that the low number of coral genera identified in $1.0 \mathrm{~m}$ camera distance because observer unable to identify rare and small size coral, thus resulting in a higher number of (b) coral growth form identified. This is because such rare coral was identified only to its growth form category. As suggested, closer the camera distance from substrate will be more appropriate for coral identification [15]. Detailed in type of coral genera identified by different vertical camera distance was listed in Table 4 .

Overall, video recorded at $1.0 \mathrm{~m}$ camera distance spent lesser time to complete the survey but have a lower taxonomic resolution for identification of benthic categories. The higher analytical effort was measured when the video was taken at $0.2 \mathrm{~m}$ camera distance because more frames need to be extracted, resulting longer time spent during data analysis. Therefore, $0.5 \mathrm{~m}$ was chosen as an optimized protocol for CVT technique as it can cover greater area and extracts fewer frames than $0.2 \mathrm{~m}$ as well as can detect more benthic categories than using $1.0 \mathrm{~m}$ camera distance for CVT technique.
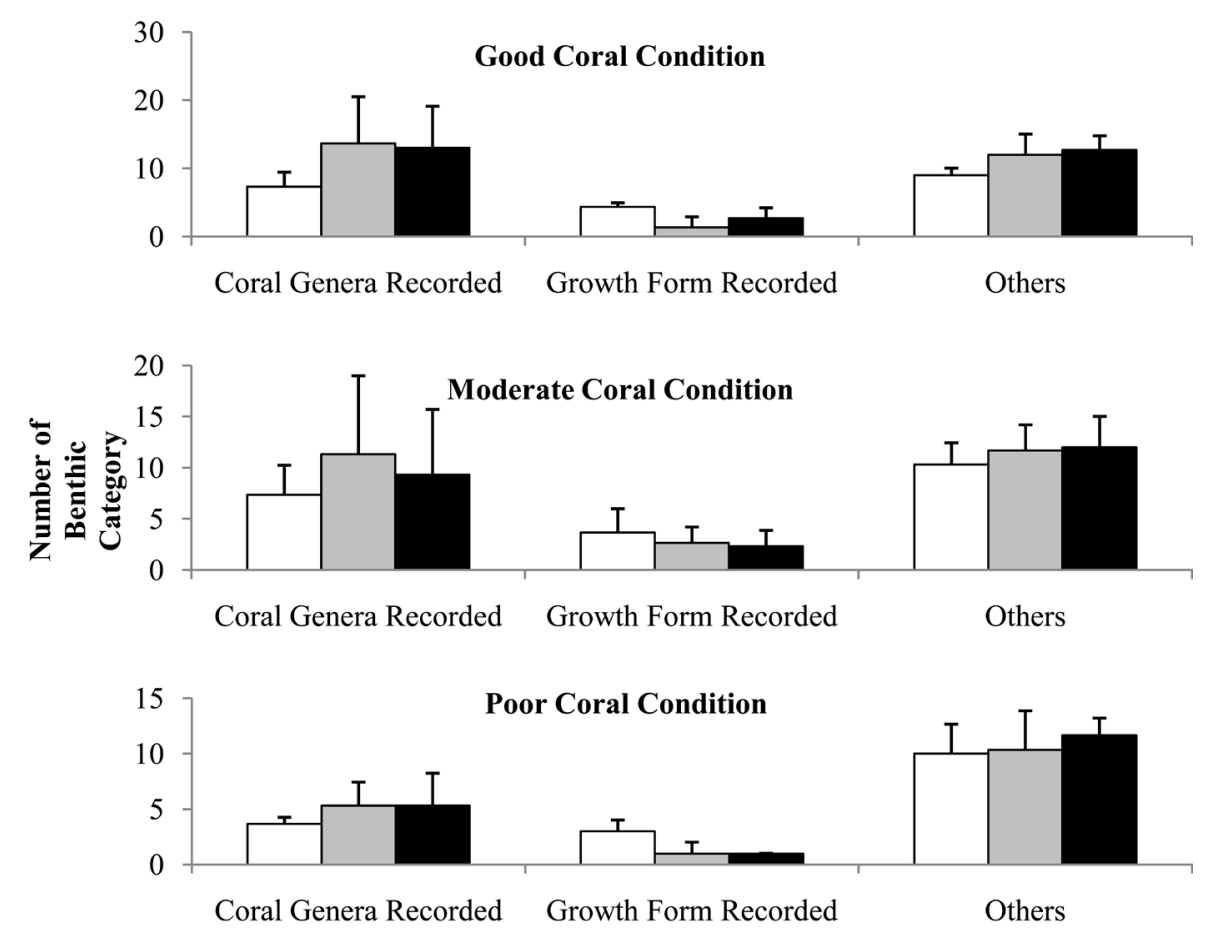

(a)

(b)

(c)

$$
\square 1.0 \mathrm{~m} \quad \square(0.5 \mathrm{~m} \quad \square 0.2 \mathrm{~m}
$$

Figure 4. Comparison number of major benthic categories; (a) coral genera, (b) coral growth form and (c) others categories determine at a different camera distance from the substrate $(1.0 \mathrm{~m}, 0.5 \mathrm{~m}$ and $0.2 \mathrm{~m})$ at good, moderate and poor coral reef condition. Values are Mean $\pm \mathrm{SD}, \mathrm{n}=3$. 
Table 4. List of coral genera and total number of identified coral genera by different camera distance from the substrate (1.0 $\mathrm{m}, 0.5 \mathrm{~m}$ and $0.2 \mathrm{~m}$ ) at different coral reef conditions (good, moderate and poor). Coral genera identify was denoted as " $\mathrm{X}$ " and not identified as “-”.

\begin{tabular}{|c|c|c|c|c|c|c|c|c|c|}
\hline \multirow{2}{*}{ Categories } & \multicolumn{3}{|c|}{ Good } & \multicolumn{3}{|c|}{ Moderate } & \multicolumn{3}{|c|}{ Poor } \\
\hline & $1.0 \mathrm{~m}$ & $0.5 \mathrm{~m}$ & $0.2 \mathrm{~m}$ & $1.0 \mathrm{~m}$ & $0.5 \mathrm{~m}$ & $0.2 \mathrm{~m}$ & $1.0 \mathrm{~m}$ & $0.5 \mathrm{~m}$ & $0.2 \mathrm{~m}$ \\
\hline Acropora (ACP) & $\mathrm{X}$ & $\mathrm{X}$ & $\mathrm{X}$ & $\mathrm{X}$ & $\mathrm{X}$ & $\mathrm{X}$ & $\mathrm{X}$ & $\mathrm{X}$ & $\mathrm{X}$ \\
\hline Alveopora (ALVEO) & - & $\mathrm{X}$ & - & - & - & - & - & $\mathrm{X}$ & - \\
\hline Astreopora (AST) & - & $\mathrm{X}$ & $\mathrm{X}$ & - & - & - & - & - & - \\
\hline Caulastrea (CAU) & - & - & - & - & - & - & $\mathrm{X}$ & - & - \\
\hline Ctenactis (CTENA) & $\mathrm{X}$ & $\mathrm{X}$ & $\mathrm{X}$ & $\mathrm{X}$ & $\mathrm{X}$ & $\mathrm{X}$ & $\mathrm{X}$ & - & $\mathrm{X}$ \\
\hline Cycloseris (CYCLO) & $\mathrm{X}$ & $\mathrm{X}$ & $\mathrm{X}$ & - & $\mathrm{X}$ & $\mathrm{X}$ & - & - & - \\
\hline Cyphastrea (СYPHA) & - & $\mathrm{X}$ & $\mathrm{X}$ & - & $\mathrm{X}$ & $\mathrm{X}$ & - & - & - \\
\hline Diploastrea (DIPLO) & $\mathrm{X}$ & $\mathrm{X}$ & - & - & - & - & - & - & - \\
\hline Echinopora (ECHI) & $\mathrm{X}$ & $\mathrm{X}$ & $\mathrm{X}$ & - & $\mathrm{X}$ & - & - & - & - \\
\hline Favia (FAV) & - & $\mathrm{X}$ & $\mathrm{X}$ & - & $\mathrm{X}$ & $\mathrm{X}$ & - & - & - \\
\hline Favites (FAVI) & - & $\mathrm{X}$ & $\mathrm{X}$ & - & $\mathrm{X}$ & $\mathrm{X}$ & - & $\mathrm{X}$ & $\mathrm{X}$ \\
\hline Fungia (FUN) & $\mathrm{X}$ & $\mathrm{X}$ & $\mathrm{X}$ & $\mathrm{X}$ & $\mathrm{X}$ & $\mathrm{X}$ & $\mathrm{X}$ & $\mathrm{X}$ & $\mathrm{X}$ \\
\hline Galaxea (GAL) & - & $\mathrm{X}$ & $\mathrm{X}$ & - & $\mathrm{X}$ & $\mathrm{X}$ & - & $\mathrm{X}$ & $\mathrm{X}$ \\
\hline Goniastrea (GON) & - & $\mathrm{X}$ & $\mathrm{X}$ & - & $\mathrm{X}$ & $\mathrm{X}$ & - & - & - \\
\hline Goniopora (GONIO) & $\mathrm{X}$ & $\mathrm{X}$ & $\mathrm{X}$ & - & - & - & - & - & - \\
\hline Halomitra (HALO) & - & - & - & - & $\mathrm{X}$ & $\mathrm{X}$ & - & - & - \\
\hline Herpolitha (HER) & $\mathrm{X}$ & $\mathrm{X}$ & $\mathrm{X}$ & - & $\mathrm{X}$ & $\mathrm{X}$ & - & - & - \\
\hline Hydnophora (HYDNO) & - & $\mathrm{X}$ & $\mathrm{X}$ & - & - & - & - & - & - \\
\hline Lobophyllia (LOBO) & - & $\mathrm{X}$ & - & - & - & - & - & - & - \\
\hline Merulina (MERU) & - & $\mathrm{X}$ & $\mathrm{X}$ & - & $\mathrm{X}$ & $\mathrm{X}$ & - & $\mathrm{X}$ & $\mathrm{X}$ \\
\hline Montastrea (MONTA) & - & - & - & $\mathrm{X}$ & - & - & - & - & - \\
\hline Montipora (MON) & $\mathrm{X}$ & $\mathrm{X}$ & $\mathrm{X}$ & $\mathrm{X}$ & $\mathrm{X}$ & $\mathrm{X}$ & - & - & - \\
\hline Pachyseris (PACHY) & - & - & - & - & $\mathrm{X}$ & $\mathrm{X}$ & - & - & - \\
\hline Pavona (PAV) & $\mathrm{X}$ & $\mathrm{X}$ & $\mathrm{X}$ & $\mathrm{X}$ & $\mathrm{X}$ & $\mathrm{X}$ & $\mathrm{X}$ & $\mathrm{X}$ & $\mathrm{X}$ \\
\hline Pectinia (PEC) & $\mathrm{X}$ & $\mathrm{X}$ & $\mathrm{X}$ & - & - & - & - & - & - \\
\hline Physogyra (PHY) & $\mathrm{X}$ & $\mathrm{X}$ & $\mathrm{X}$ & $\mathrm{X}$ & $\mathrm{X}$ & - & - & - & - \\
\hline Platygyra (PLATY) & $\mathrm{X}$ & $\mathrm{X}$ & - & - & $\mathrm{X}$ & $\mathrm{X}$ & - & - & - \\
\hline Plerogyra (PLERO) & - & $\mathrm{X}$ & - & - & - & - & - & - & - \\
\hline Pocillopora (POCL) & $\mathrm{X}$ & $\mathrm{X}$ & $\mathrm{X}$ & $\mathrm{X}$ & $\mathrm{x}$ & $\mathrm{x}$ & $\mathrm{X}$ & $\mathrm{X}$ & $\mathrm{X}$ \\
\hline Porites (PORI) & $\mathrm{X}$ & $\mathrm{X}$ & $\mathrm{X}$ & $\mathrm{X}$ & $\mathrm{X}$ & $\mathrm{X}$ & - & $\mathrm{X}$ & $\mathrm{X}$ \\
\hline Scolymia (SCOLY) & - & - & $\mathrm{X}$ & - & - & - & - & - & - \\
\hline Symphyllia (SYMP) & - & - & - & - & $\mathrm{X}$ & - & - & - & - \\
\hline Turbinaria (TURBI) & - & $\mathrm{X}$ & $\mathrm{X}$ & - & - & - & - & - & - \\
\hline Total & 15 & 27 & 23 & 9 & 21 & 18 & 6 & 9 & 9 \\
\hline
\end{tabular}

\subsection{Sample Size Optimization}

Figure 5 showed that the precision tends to decrease rapidly from $50 \%$ to $20 \%$ number of frames extracted at different coral reef conditions. However, precision in estimating percent cover of (b) ALG and (c) OT did not relatively change as the number of frames decrease at good and moderate coral conditions. High precision in estimating percent cover of benthic categories was detected from 100\% to $80 \%$ number of frames. Figure 6 compared numbers of major benthic categories of (a) coral genera, (b) coral growth form and (c) other categories 
determine at different number of frames extracted. Roughly, mean number of all types of major benthic categories identified tends to decrease as the number of frames extracted decreases. Total number of (a) coral genera, (b) coral growth form and (c) other categories identified tends to decrease rapidly from $50 \%$ to $20 \%$ number frames extracted in all coral reef conditions and remain almost constant at $80 \%$ until the baseline value.

In order to finalize the protocol for data analysis from CVT technique, an optimum number of points analyzed
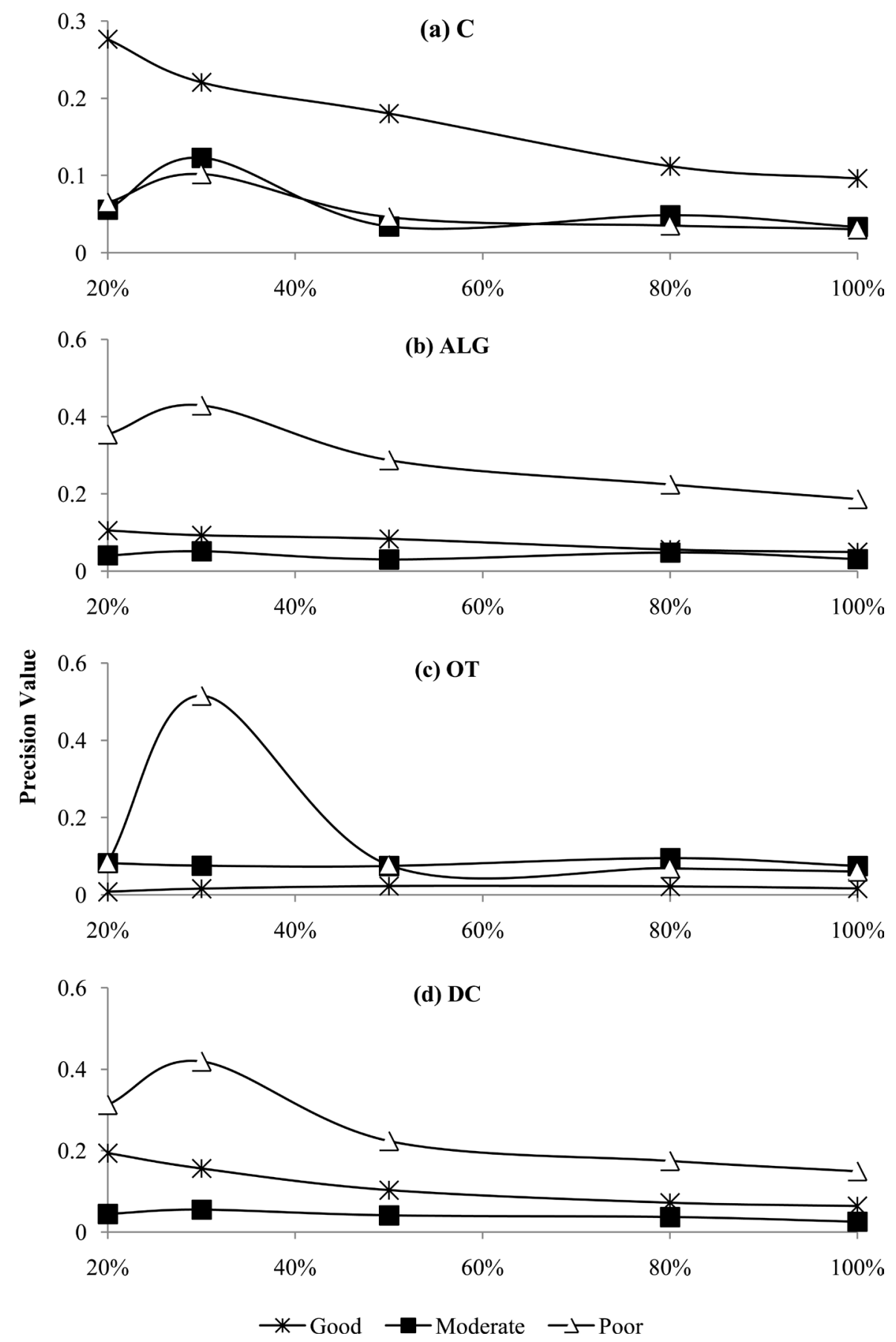

Figure 5. Precision value for percent cover of different benthic categories (a) coral (C), (b) algae (ALG), (c) other invertebrates (OT) and (d) Dead Coral (DC) at the different number of non-overlapping frames extracted (20\%, 30\%, 50\%, 80\% and $100 \%$ frames of $20 \mathrm{~m}$ transect) at good, moderate and poor coral reef condition. Precision was calculated by $s / \sqrt{n} \quad(s=$ standard deviation, $n=$ total number of points analysed). 

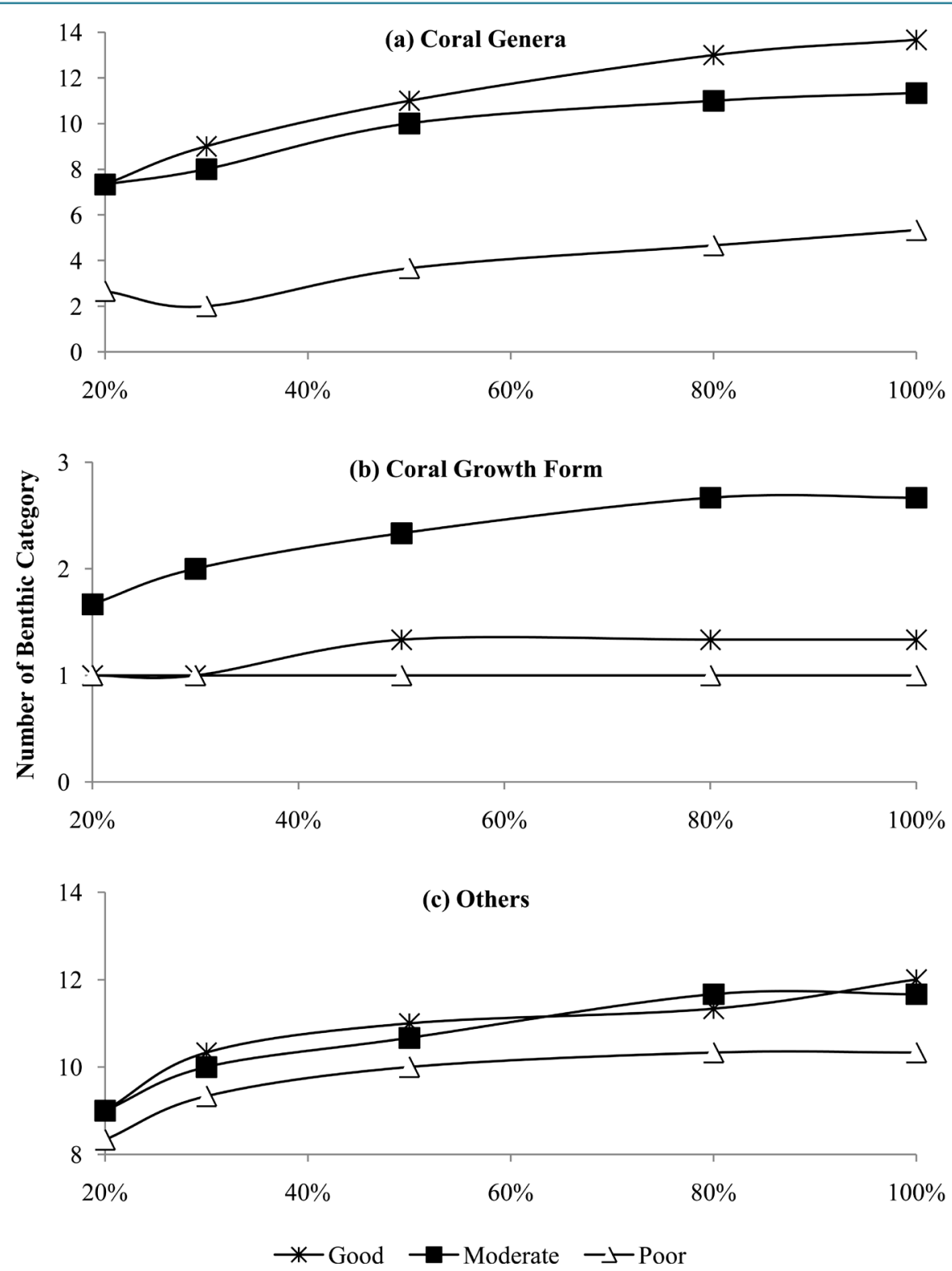

Figure 6. Comparison number of major benthic categories of (a) coral genera, (b) coral growth form and (c) other categories determine at different number of frames extracted (20\%, 30\%, 50\%, 80\% and $100 \%$ frames of $20 \mathrm{~m}$ transect) at good, moderate and poor coral reef condition. Values are Mean, $\mathrm{n}=3$.

were determined. Precision values obtained by different number of points were shown in Figure 7. Roughly, the result showed that the precision in estimating percent cover of (a) C, (b) ALG, (c) DC and (d) OT categories in Figure 7 tend to decrease slowly from true value until 50 and rapidly decrease from 30 to 5 points at all coral reef conditions. A relatively small change in mean number of major benthic categories identified by different number of points was then illustrated in Figure 8. The value tends to remain constant from 300 to 50 points per frame and then decrease from 30 to 5 points for the total number of benthic categories identified. Respectively, the results showed that the precision and the mean number of identified categories decrease from 30 to 5 points and remain almost constant at 50 until 300 points at all types of coral reef conditions.

Our results indicated that the variation between the precision value in the sample size decrease rapidly after $80 \%$ of the total number of frames extracted and 50 points per frames analyzed. In such situations, the minimum acceptable number of frames extracted and points analyzed occurs at the point where the rate of change in the variation of the precision value is sharply reduced [26]. Therefore the protocol for CVT technique was by re- 
cording video along $20 \mathrm{~m}$ transect at $0.5 \mathrm{~m}$ camera distance from the substrate and the video should be extracted with approximately $80 \%$ from total frames extracted as well as analyzed with 50 points per frames during CPCe analysis.
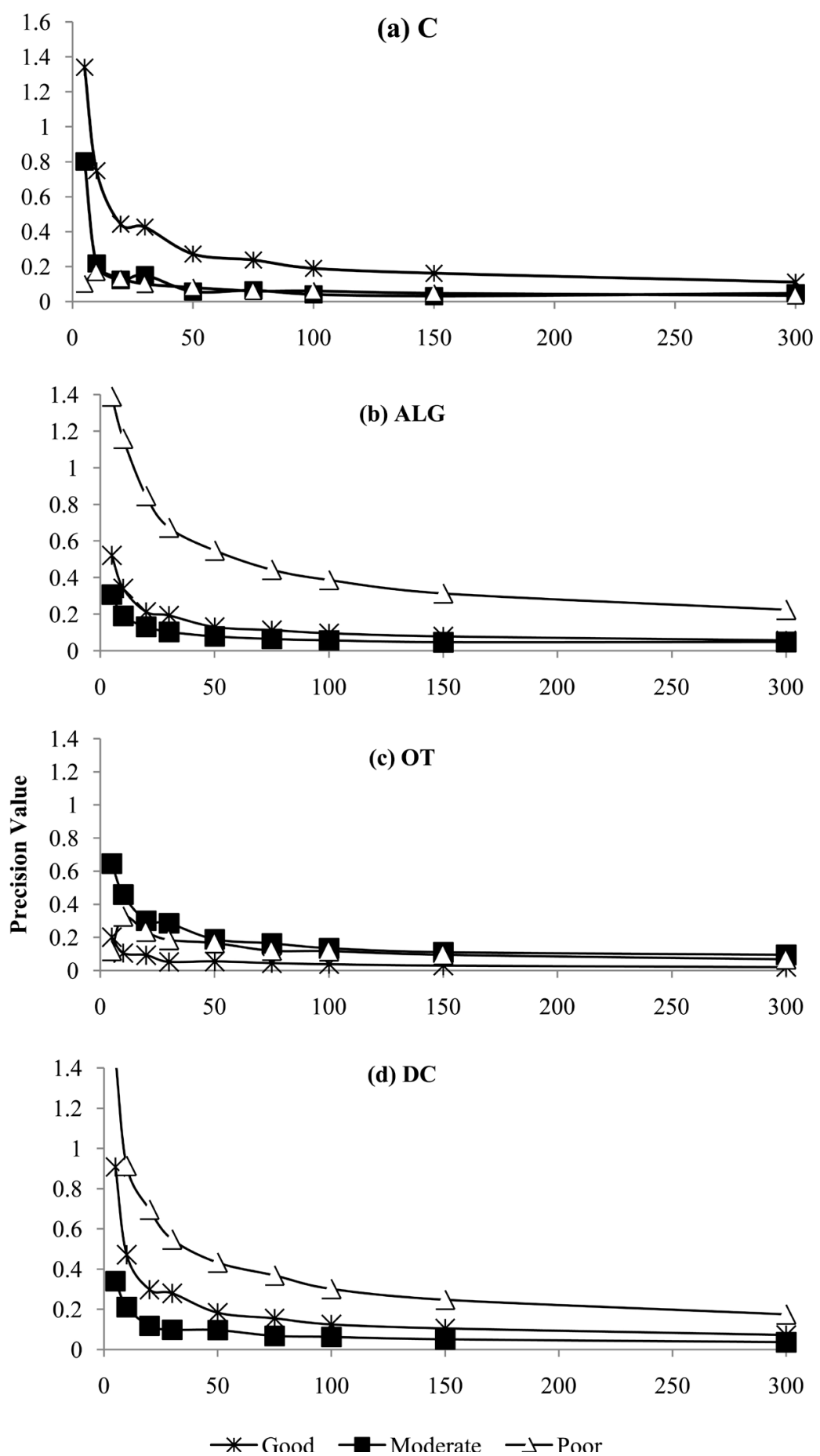

Figure 7. Precision value for percentage cover of different major benthic categories of (a) coral (C), (b) algae (ALG), (c) other invertebrates (OT) and (d) dead coral (DC) at different number points analysed (300, 150, 100, 75, 50, 30, 20, 10 and 5 points per frame) at good, moderate and poor coral reef condition. Precision was calculated by $s / \sqrt{n} \quad(s=$ standard deviation, $n=$ total number of points analysed). 

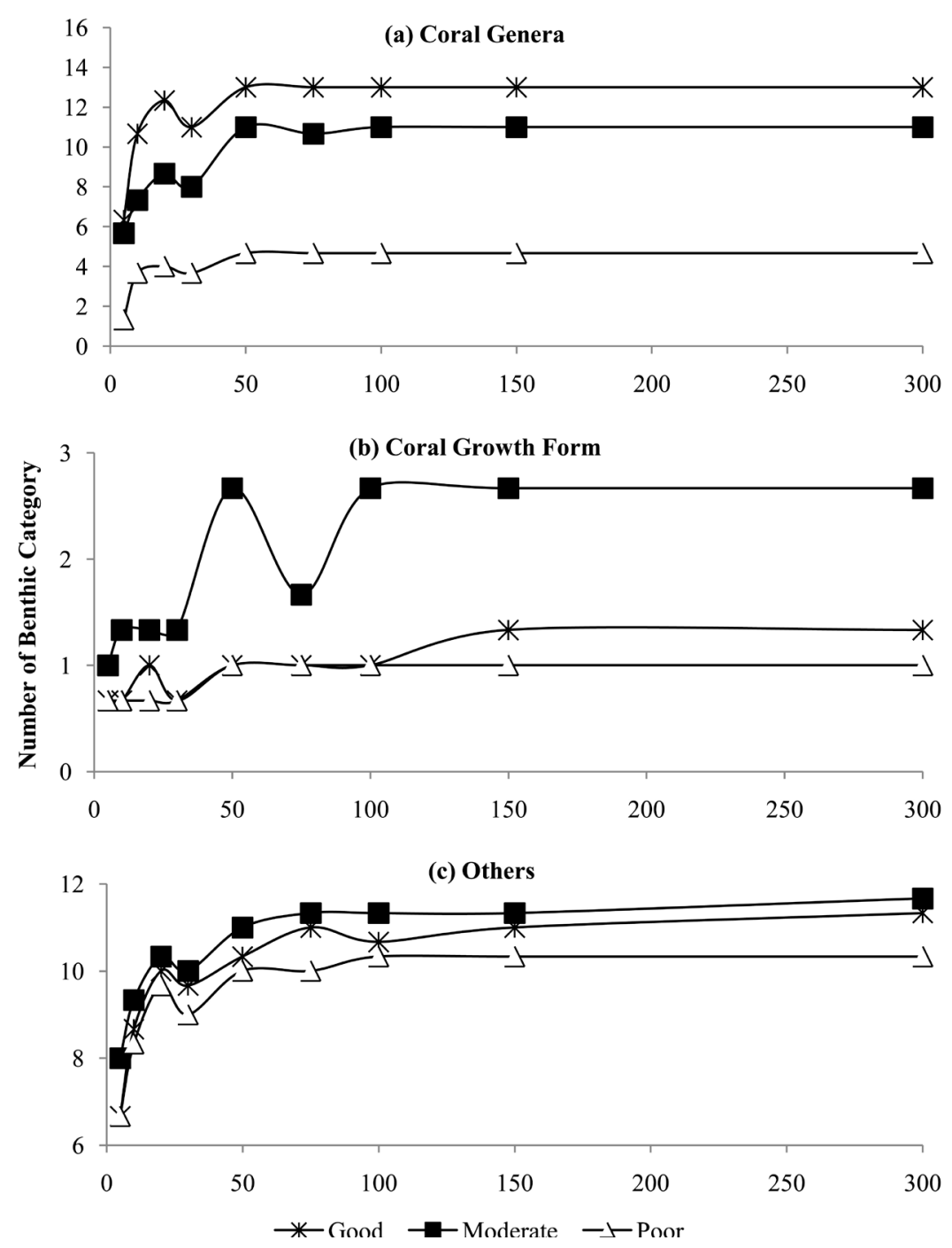

Figure 8. Comparison of the total number of benthic categories of (a) coral genera, (b) coral growth form and (c) other categories determines at different number of points analysed (300, 150, 100, 75, 50, 30, 20, 10 and 5 points per frames) at good, moderate and poor coral reef condition. Values are Mean, $n=3$.

There were also several studies on comparing different number of frames and points analyzed for video sampling to detect change in coral cover [17] [19]. Video recording at $0.5 \mathrm{~m}$ camera distance along $10 \mathrm{~m}$ transect and analyzed with a total of 20 frames with 50 points per frames was used to monitor long-term changes in coral reef benthic communities in Hawai'i [17]. Equivalent to $10 \mathrm{~m}$ transect, this study used 25 frames per $10 \mathrm{~m}$ transect which is more frames than [17]. In fact, heterogeneity of the substrate can be achieved by adding more frames [17]. Moreover, the use of 50 points per frames analyzed can accurately describe the coral reef habitat [17]. Besides that, this study covers a far greater area per frames $\left(0.1 \mathrm{~m}^{2}\right.$ per frames) although both use similar camera distance from the substrate $(0.5 \mathrm{~m})\left(0.075 \mathrm{~m}^{2}\right.$ area per frames [17]). This might happen due to the different camera lens used within both studies.

Long term monitoring by the Commonwealth of the Northern Mariana Islands conducted video recording at a vertical distance of $0.5 \mathrm{~m}$ above the substrate and used 60 frames with 5 points per frames during data analysis [19]. Equivalent to $1 \mathrm{~m}$ transect, this study extracts more frames (2.5 frames/m) than previous studies (1.2 frames/m [19]). Lower number of points analyzed can avoid from autocorrelation (more points overlay at single organism) but give lower value for species evenness since less common or smaller corals were not adequately represented [17]. Generally, evenness is a proportion of the number of organisms count. Hence, using lower points will detect the less number of benthic categories. In this situation, lower number of points can cause a 
false impression of coral communities [17]. Moreover, an accurate estimate of percent cover at the area with lower cover can be achieved by using more points/frames [30]. Therefore, the use of 50 points per frame in this study might be able to record more benthic categories than 5 points per frames.

\subsection{Evaluation of CVT Optimize Protocol}

In Figure 9, no significant difference was found in estimating percent over of (a) C and (d) DC by CVT and LIT method ( $p>0.05$ ). Previous study also found no clear difference in percentage cover of coral estimated by using a video technique and PIT method ( $p>0.05$ ) [9]. LIT tends to estimate relatively lower cover of the (b) ALG in almost all transect except at T1 (LIT $=7.1 \% \pm 1.79 \%$, CVT $=5.93 \% \pm 2.52 \%)$ as compared to CVT method. There was a significant difference in estimating percent cover of ALG in T4 (p < 0.05) whereas CVT $(16.47 \% \pm$ $2.22 \%)$ recorded a significantly higher cover of ALG compared to the LIT method $(2.03 \% \pm 4.07 \%) \mathrm{t}(6)=$ $-6.23, \mathrm{p}=0.001$.

Our findings showed that LIT method tends to estimate relatively higher percentage cover of coral (except in T1) than CVT method. A study reported that the conventional LIT method tends to overestimate live coral cover than video method [15] [28]. Higher estimate generated by LIT was due to the contour effect when the transect tape tends to follow the contours of larger coral colonies, thereby estimating the circumferential length of the coral, thus overestimates live coral cover [28]. Besides that, it was difficult to measure branching coral by the LIT method as the observer tends to miss the small gap between the coral's branches and thus, under/overestimate its cover. Moreover, it is difficult to identify what's beneath the transect tape when the tape sway around by the current. It can only be measured when the substrate in contact even one side of the transect line [28]. Besides that, this might cause the LIT method to estimate significantly lower cover for algae than CVT method.

The CVT method might have a higher chance in detecting more benthic categories than LIT method and recorded a significantly higher cover for OT in $\mathrm{T} 1(5.7 \% \pm 1.06 \%)$ and $\mathrm{T} 6(13.73 \% \pm 5.99 \%)$ as compared to the LIT method $(\mathrm{T} 1=1.01 \pm 2.02$, T6 $=2.03 \pm 4.07)$. CVT also estimated higher cover for algae and other invertebrates because small organisms (such as ascidians and sea shells) can be easily counted with the use of the point count method as compared to LIT which need to measure the length of organisms below the tape. For example, it is hard to measure the Drupella snails that live on the branches of Acropora coral by LIT method.

Relatively, CVT (35 coral genus) recorded more coral genus in all transects as compared to LIT (30 coral genus) as shown in Table 5. However, no clear difference was found in estimating the number of Figure 10(a) coral genera by both methods $(\mathrm{p}>0.05)$ as shown in Figure 10. CVT significantly recorded the highest number of Figure 10(b) coral growth form at T1 (1.5 \pm 0.57$)$, T4 (2.75 \pm 0.96$)$ and T6 (1.5 \pm 0.58$)$ transect compared to the LIT method $(\mathrm{T} 1=0.25 \pm 0.5, \mathrm{~T} 4=0, \mathrm{~T} 6=0.25 \pm 0.5)(\mathrm{p}<0.05)$ (Figure 10). CVT also recorded significantly higher value for a number of Figure 10(c) other categories identified than the LIT method at all transects $(p<0.05)$ as shown in Figure 10. The total number of other categories identified from all transect showed that CVT (22 categories) able to record more other categories than LIT method (17 categories) as shown in Table 6.

The video method record swathe of the substrate, thus the benthic categories are more likely to be identified than LIT method which only identified benthic categories beneath the transect tape along a transect line. Moreover, it appears that LIT tends to detect less number of categories than CVT method due to small area cover. However, VIDEO technique recorded fewer genera than LIT [28]. The dissent between these studies might come from disability of video technique to clearly detect coral genera from the video taken. Our study able to identify more coral genera due to the identification of benthic categories was made before the analysis of video images. Furthermore, both methods were analyzed by same person repeatedly. Therefore, the observer has the experience for identification of coral either during in-situ or from video recording.

During the (a) field survey, CVT method able to accomplish more quickly to film each $20 \mathrm{~m}$ transect as compared to the LIT method as shown in Figure 11. The CVT method took significantly lower time $(\mathrm{p}<0.05)$ during a) field survey ( $6 \pm 0$ minutes) than the LIT method ( $21.25 \pm 2.5$ minutes). As compared to LIT method, in 60 min dive it was possible to survey twice $20 \mathrm{~m} \times 4$ segments transect by using CVT method while only one transect might be able to survey using LIT method. Thus, in one day sampling, the CVT can accomplish six transect while LIT only three transect per day if the divers manage to do three dive per day. The video sampling was proved to be more time efficient than the LIT method (VIDEO = one day per depth per site over a LIT = 8 day per depth per site) [28]. Several authors have stated that video sampling along a transect line is clearly the fastest method to survey coral reef [3] [9] [15] [17]. 

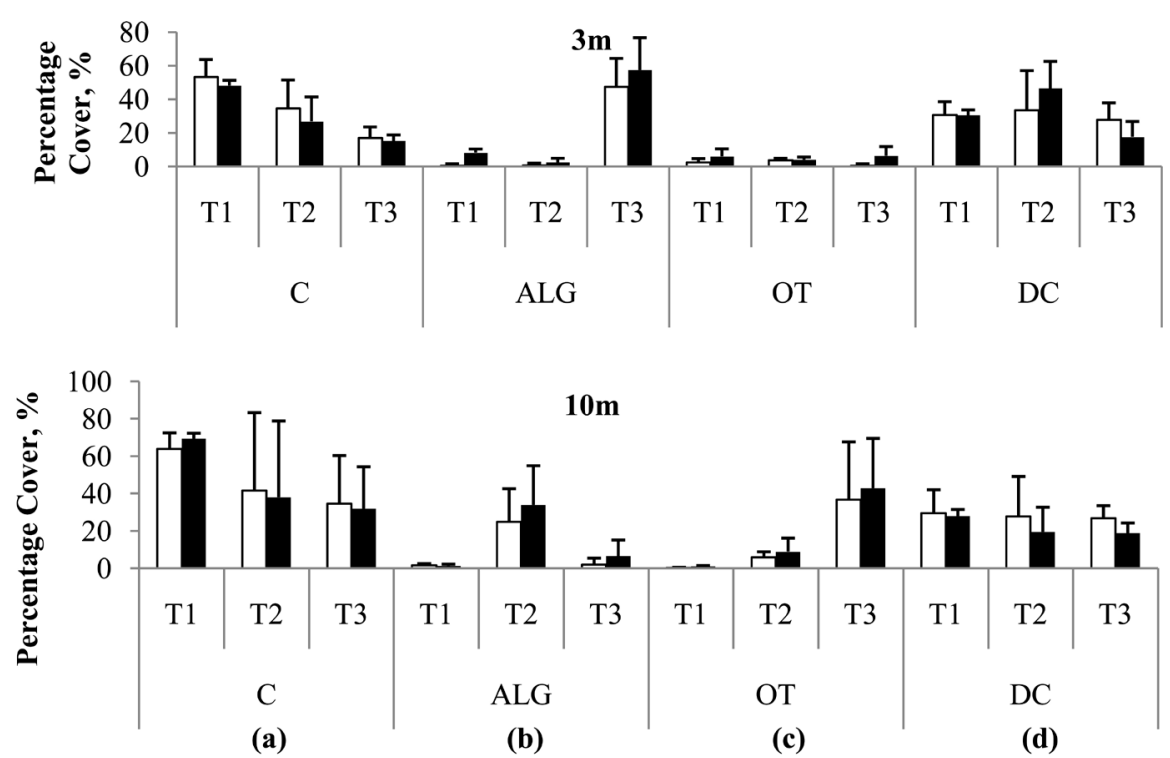

口LIT $\square \mathrm{CVT}$

Figure 9. Comparison of percentage benthic cover (\%) of (a) coral (C), (b) algae (ALG), (c) other invertebrates (OT) and (d) dead coral (DC) determine by LIT and CVT method along $20 \mathrm{~m} \times 4$ segments transect by different depth (3 $\mathrm{m}$ and $10 \mathrm{~m}$ transect). Values are Mean $\pm \mathrm{SD}, \mathrm{n}=4$.
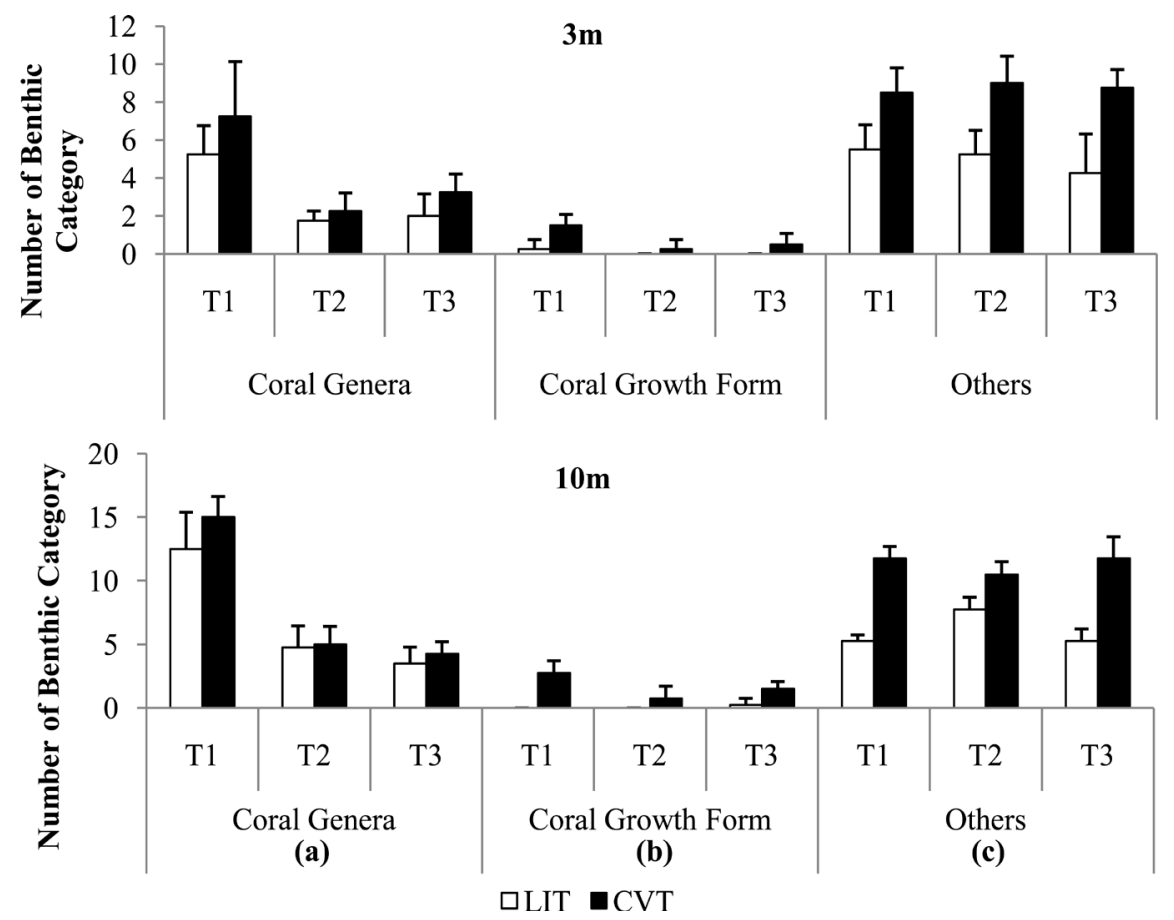

Figure 10. Comparison of the total number of benthic categories of (a) coral genera, (b) coral growth form, and (c) other categories identified by LIT and CVT method along $20 \mathrm{~m} \times 4$ segments transect by the different depths $(3 \mathrm{~m}$ and $10 \mathrm{~m}$ transect). Values are Mean $\pm \mathrm{SD}, \mathrm{n}=4$.

However, CVT methods spent significantly longer time during (b) data processing and (c) data analysis ( $<$ < 0.05) as compared to the LIT method. Corresponding to this, video technique spent longer time than LIT method when the time taken to record and analyze the data is considered [17]. Perhaps, the most serious drawback of this technique is that video taken need to be extracted and identification was done after the fieldwork as compared to LIT, which directly identify benthic categories in-situ. LIT only spent on time taken during duplication 
of the data collected to a computer and calculate the percentage cover of benthic categories recorded. Meanwhile, analysis of video was done by an observer using a computer through CPCe software. Thus, if the time consuming only counts the manpower effort, thus we can directly ignore the time taken during data processing for CVT method as it was automatically done by CPCe software.

Table 5. List of coral genera and total number of coral genera identified by using optimized CVT and LIT method at all surveyed transect (T1 until T6). Coral genera identify was denoted as "X" and not identify as “-”.

\begin{tabular}{|c|c|c|c|}
\hline Categories & Subcategories & LIT & CVT \\
\hline \multirow{39}{*}{ Coral } & Acropora (ACP) & $\mathrm{X}$ & $\mathrm{X}$ \\
\hline & Astrepora (AST) & $\mathrm{X}$ & $\mathrm{X}$ \\
\hline & Barabattoia (BARA) & - & $\mathrm{X}$ \\
\hline & Millepora (CME) & $\mathrm{X}$ & $\mathrm{X}$ \\
\hline & Ctenactis (CTENA) & $\mathrm{X}$ & $\mathrm{X}$ \\
\hline & Cycloseris (CYCLO) & $\mathrm{X}$ & $\mathrm{X}$ \\
\hline & Cyphastrea (СYPHA) & $\mathrm{X}$ & $\mathrm{X}$ \\
\hline & Diploastrea (DIPLO) & $\mathrm{X}$ & $\mathrm{X}$ \\
\hline & Echinopora (ECHI) & $\mathrm{X}$ & $\mathrm{X}$ \\
\hline & Euphyllia (EUP) & - & $\mathrm{X}$ \\
\hline & Favia (FAV) & $\mathrm{X}$ & $\mathrm{X}$ \\
\hline & Favites (FAVI) & $\mathrm{X}$ & $\mathrm{X}$ \\
\hline & Fungia (FUN) & $\mathrm{X}$ & $\mathrm{X}$ \\
\hline & Galaxea (GAL) & $\mathrm{X}$ & $\mathrm{X}$ \\
\hline & Gardineroseris (GAR) & $\mathrm{X}$ & $\mathrm{X}$ \\
\hline & Goniastrea (GON) & $\mathrm{X}$ & $\mathrm{X}$ \\
\hline & Goniopora (GONIO) & $\mathrm{X}$ & $\mathrm{X}$ \\
\hline & Hydnophora (HYDNO) & $\mathrm{X}$ & $\mathrm{X}$ \\
\hline & Leptastrea (LEPTA) & - & $\mathrm{X}$ \\
\hline & Leptoseris (LEPTO) & - & $\mathrm{X}$ \\
\hline & Lobophyllia (LOBO) & $\mathrm{X}$ & $\mathrm{X}$ \\
\hline & Merulina (MERU) & $\mathrm{X}$ & $\mathrm{X}$ \\
\hline & Montastrea (MON) & $\mathrm{X}$ & $\mathrm{X}$ \\
\hline & Oulastrea (OULA) & $\mathrm{X}$ & - \\
\hline & Oulophyllia (OULOP) & - & $\mathrm{X}$ \\
\hline & Pachyseris (PACHY) & $\mathrm{X}$ & - \\
\hline & Pavona (PAV) & $\mathrm{X}$ & $\mathrm{X}$ \\
\hline & Physogyra (PHY) & $\mathrm{X}$ & $\mathrm{X}$ \\
\hline & Platygyra (PLATY) & $\mathrm{X}$ & $\mathrm{X}$ \\
\hline & Pocillopora (POCL) & $\mathrm{X}$ & $\mathrm{X}$ \\
\hline & Podabacia (PODA) & - & $\mathrm{X}$ \\
\hline & Porites (PORI) & $\mathrm{X}$ & $\mathrm{X}$ \\
\hline & Symphyllia (SYMP) & $\mathrm{X}$ & - \\
\hline & Turbinaria (TURBI) & $\mathrm{X}$ & $\mathrm{X}$ \\
\hline & Unknown Encrusting Coral (UEC) & $\mathrm{X}$ & $\mathrm{X}$ \\
\hline & Unknown Free Living/Solitary Coral (UFS) & $\mathrm{X}$ & $\mathrm{X}$ \\
\hline & Unknown Massive Coral (UMS) & - & $\mathrm{X}$ \\
\hline & Uknown Plate Foliose Coral (UPF) & - & $\mathrm{X}$ \\
\hline & Total & 30 & 35 \\
\hline
\end{tabular}


Table 6. List of benthic categories such as algae, other categories, dead coral and abiotic substrate (sand, silt, rock) and total number of categoris identified by using optimized CVT and LIT method at all surveyed transect (T1 until T6). Benthic categories identify was denoted as "X” and not identify as “-”.

\begin{tabular}{|c|c|c|c|}
\hline Categories & Subcategories & LIT & CVT \\
\hline \multirow{10}{*}{ Algae } & Other Algae (AA) & $\mathrm{X}$ & $\mathrm{X}$ \\
\hline & Crustose Coralline Algae (CCA) & $\mathrm{X}$ & $\mathrm{X}$ \\
\hline & Halimeda (HA) & - & $\mathrm{X}$ \\
\hline & Lobophora (LOB) & $\mathrm{X}$ & $\mathrm{X}$ \\
\hline & Padina (PA) & $\mathrm{X}$ & $\mathrm{X}$ \\
\hline & Turf Algae (TA) & $\mathrm{X}$ & $\mathrm{X}$ \\
\hline & Anemone (ANE) & $\mathrm{X}$ & $\mathrm{X}$ \\
\hline & Ascidian (ASC) & - & $\mathrm{X}$ \\
\hline & Giant Clam (GC) & $\mathrm{X}$ & $\mathrm{X}$ \\
\hline & Other Invertebrates (OT) & $\mathrm{X}$ & $\mathrm{X}$ \\
\hline \multirow[t]{7}{*}{ Other Categories } & Sea Cucumber (SC) & $\mathrm{X}$ & $\mathrm{X}$ \\
\hline & Sea Shell (SH) & - & $\mathrm{X}$ \\
\hline & Sponge (SP) & $\mathrm{X}$ & $\mathrm{X}$ \\
\hline & Sea Star / Cushion Star (SS) & - & $\mathrm{X}$ \\
\hline & Zooanthid (Z) & $\mathrm{X}$ & $\mathrm{X}$ \\
\hline & Bleached Coral (BC) & - & $\mathrm{X}$ \\
\hline & Dead Coral (DC) & $\mathrm{X}$ & $\mathrm{X}$ \\
\hline \multirow{4}{*}{ Dead Coral } & Dead Coral with Algae (DCA) & $\mathrm{X}$ & $\mathrm{X}$ \\
\hline & Diseased Coral (DS) & $\mathrm{X}$ & $\mathrm{X}$ \\
\hline & Rubble (R) & $\mathrm{X}$ & $\mathrm{X}$ \\
\hline & Recently Dead Coral (RDC) & - & $\mathrm{X}$ \\
\hline \multirow{3}{*}{ Sand, Silt, Rock } & Rock & $\mathrm{X}$ & - \\
\hline & Sand & $\mathrm{X}$ & $\mathrm{X}$ \\
\hline & Total & 17 & 22 \\
\hline
\end{tabular}

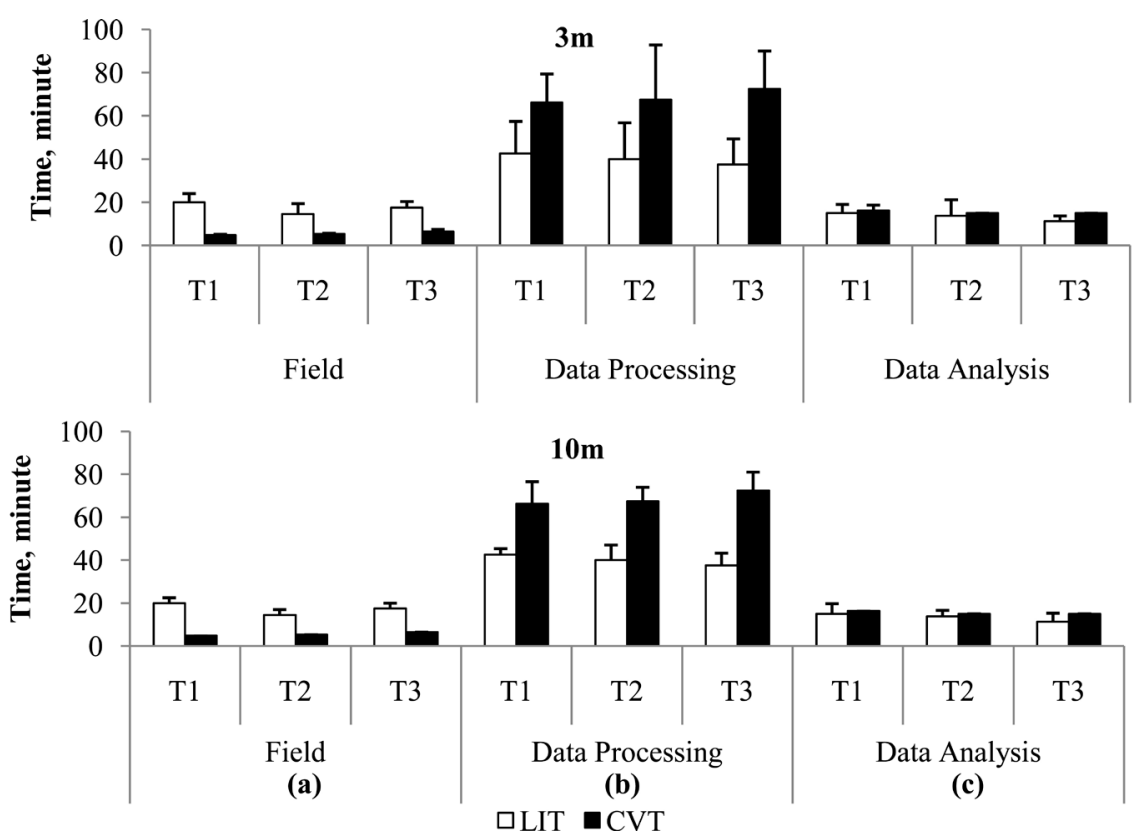

Figure 11. Comparison of time consuming among coral survey methods (LIT and CVT) between (a) field survey, (b) data processing and (c) data analysis (minutes) at a depth of $3 \mathrm{~m}$ and $10 \mathrm{~m}$ transect. Values are Mean $\pm \mathrm{SD}, \mathrm{n}=4$. 
It is apparent that the optimized CVT technique able to estimate percentage covers of benthic categories relatively similar to LIT method, but capable to reduce the time spent underwater and identify more benthic categories as compared to LIT method. Therefore, the protocol for CVT technique is suitable to be used for coral reef survey. Other advantages of using this technique include provision of permanent record, and wider survey area than field transect method such as LIT method.

\section{Conclusions}

The benthic monitoring program should be directed at the development and evaluation of statistically valid sampling protocols that meet the local requirements. In this study, Coral Video Transect (CVT) method adapted from [12] was modified so that it can fit the reef system in Malaysia. By using this protocol, it has the ability to the estimate percentage cover of benthic categories similar to LIT method. The advantages of this technique are it took shorter time during field survey, able to cover wider area and detects more benthic categories as compared to LIT method. In 60 minutes diving, it might able to completely survey two $20 \mathrm{~m} \times 4$ segments transects. If cost of diving trip for a whole day is considered, the CVT can end up with six transect rather than LIT which only able to survey three transect if three dives were done in a whole day. Thus LIT method needs at least two days to survey similar number of transect as CVT method which consequently will double the cost of the survey. Considering the expertise needed during underwater coral reef survey, and regardless of the time spent in data analysis by LIT or other methods such as Point Intercept Transect (PIT) used by Reef Check Malaysia, the results accordingly suggested that the CVT technique might be accepted to study the status of coral reef ecosystem in Malaysia.

Overall, several limitations were found which might affect the outcome of the experiment. First, the used of different camera lens and setting during the video survey will influence the area cover of the survey area. However, this influence was not taking into consideration within this study. Second, the number of frames extracted was differed although the video recording was taken at a constant camera distance from the substrate. This happened because it was difficult to precisely maintain the camera perpendicularly along the transect line even though a reference bar was used to aid in maintaining the distance of camera from the substrate during video recording. Moreover, recording was done by following the reef floor contour rather than the shape of the corals. Consequently, possibility to shoot a video closer to the coral might happen. Third, long hours were needed to analyze the data. Therefore, in order to run the analysis by CPCe software, it would be much preferred to use a computer with high capabilities to withstand huge amount of data as it might reduce time taken during data analysis. Lastly, the CVT technique conducted in this study only survey a horizontal reef floor, thus it is recommended to attempt the CVT technique for a vertical reef floor to prove the ability of CVT technique to conduct coral survey at various reef conditions.

\section{Acknowledgements}

This study was supported by a Higher Institution Centre of Excellence (HICoE), Ministry of Higher Education Malaysia, Institute of Oceanography and Environment, Universiti Malaysia Terengganu. Appreciation also goes to the Department of Marine Park, Malaysia and Laguna Redang Resort Sendirian Berhad.

\section{References}

[1] Alquezar, R. and Boyd, W. (2007) Development of Rapid, Cost Effective Coral Survey Technique: Tools for Management and Conservation Planning. Journal of Coastal Conservation, 11, 105-119. http://dx.doi.org/10.1007/s11852-008-0011-1

[2] Obura, D.O. and Grimsdith, G. (2009) Resilience Assessment of Coral Reefs-Assessment Protocol for Coral Reefs, Focusing on Coral Bleaching and Thermal Stress. International Union for the Conservation of Nature and Natural Resources, 70 .

[3] Rogers, C.S. and Miller, J. (2001) Coral Bleaching, Hurricane Damage, and Benthic Cover on Coral Reefs in St. John, U.S. Virgin Islands : A Comparison of Surveys with the Chain Transect Method and Videography. Bulletin of Marine Science, 69, 459-470.

[4] Hawkin, J.P. and Robert, C.M. (1993) Effect of Recreational Scuba Diving on Coral Reefs: Trampling on Reef-Flat Communities. Journal of Applied Ecology, 30, 23-30. http://dx.doi.org/10.2307/2404267

[5] Hogson, G. (1999) A Global Assessment of Human Effects on Coral Reefs. Marine Pollution Bulletin, 38, 345-355. 
http://dx.doi.org/10.1016/S0025-326X(99)00002-8

[6] Praveena, S.M., Siraj, S.S. and Aris, A.Z. (2012) Coral Reefs Studies and Threats in Malaysia: A Mini Review. Review Environment Science Biotechnology, 11, 27-39. http://dx.doi.org/10.1007/s11157-011-9261-8

[7] English, S., Wilkinson, C. and Baker, V. (1994) Survey Manual for Tropical Marine Resources. Australian Institute of Marine Science, Townville, 34-49.

[8] Hill, J. and Wilkinson, C. (2004) Methods for Ecological Monitoring of Coral Reefs. Australian Institute of Marine Science, Townville, 117.

[9] Lam, K., Shin, P.K.S., Bradbeer, R., Randall, D., Ku, K.K.K., Hodgson, P. and Cheung, S.G. (2006) A Comparison of Video and Point Intercept Transect Methods for Monitoring Subtropical Coral Communities. Journal of Experimental Marine Biology and Ecology, 333, 115-128. http://dx.doi.org/10.1016/j.jembe.2005.12.009

[10] Nadon, M.O. and Stirling, G. (2006) Field and Simulation Analyses of Visual Methods for Sampling Coral Cover. Coral Reefs, 25, 177-185. http://dx.doi.org/10.1007/s00338-005-0074-5

[11] Nakajima, R., Nakayama, A., Yoshida, T., Rajuddin, M. and Kushairi, M. (2010) An Evaluation of Photo Line-Intercept Transect (PLIT) Method for Coral Reef Monitoring. Galaxea, Journal of Coral Reef Studies, 12, 37-44. http://dx.doi.org/10.3755/galaxea.12.37

[12] Liew, H.C., Hii, Y.S., Bachok, Z., Ibrahim, K., Wagiman, S., Chan, A.A. and Said, A. (2012) A Guide to Collecting Digital Videos for Coral Reef Surveys and Monitoring Purposes. Department of Marine Parks Malaysia, Putrajaya, 28.

[13] Dumas, P., Bertaud, A., Peignon, C., Léopold, M. and Pelletier, D. (2009) A “Quick and Clean” Photographic Method for the Description of Coral Reef Habitats. Journal of Experimental Marine Biology and Ecology, 368, 161-168. http://dx.doi.org/10.1016/j.jembe.2008.10.002

[14] Aronson, R.B., Edminds, P.J., Precht, W.F., Swanson, D.W. and Levitan, D.R. (1994) Large-Scale, Long-Term Monitoring of Caribbean Coral Reefs: Simple, Quick, Inexpensive Techniques. Atoll Research Bulletin, No. 421, 1-19. http://dx.doi.org/10.5479/si.00775630.421.1

[15] Carleton, J.H. and Done, T.J. (1995) Quantitative Video Sampling of Coral Reef Benthos: Large-Scale Application. Coral Reefs, 14, 35-46. http://dx.doi.org/10.1007/BF00304070

[16] Reef Check Malaysia (2009) Status of Coral Reefs in Malaysia. Reef Check Malaysia Bhd, Kuala Lumpur, 43.

[17] Brown, E., Cox, E., Jokiel, P., Rodgers, K., Smith, W., Tissot, B., Coles, S.L. and Hultquist, J. (2004) Development of Benthic Sampling Methods for the Coral Reef Assessment and Monitoring Program (CRAMP) in Hawai'i. Pacific Science, 58, 145-158. http://dx.doi.org/10.1353/psc.2004.0013

[18] Abdo, D., Burgess, S., Coleman, G. and Osborne, K. (2004) Surveys of Benthic Reef Communities Using Underwater Video. Australian Institute of Marine Science, Townville, 32.

[19] Houk, P. and Woesik, R.V. (2006) Coral Reef Benthic Video Surveys Facilitate Long-Term Monitoring in the Commonwealth of the Northern Mariana Islands: Toward an Optimal Sampling Strategy. Pacific Science, 60, 177-189. http://dx.doi.org/10.1353/psc.2006.0005

[20] Chou, L.M., Wilkinson, C.R. and Suraphol, S. (1994) Status of Coral Reefs in the ASEAN Region. Proceedings of the 3rd ASEAN-Australia Symposium on Living Coastal Resources, Vol. 1: Status Reviews, Australian Institute of Marine Science, Townville.

[21] Kohler, K.E. and Gill, S.M. (2006) Coral Point Count with Excel Extensions (CPCe): A Visual Basic Program for the Determination of Coral and Substrate Coverage Using Random Point Count Methodology. Computers \& Geosciences, 32, 1259-1269. http://dx.doi.org/10.1016/j.cageo.2005.11.009

[22] Veron, J.E.N. (1982) Corals of Australia and the Indo Pacific. Australian Institute of Marine Science, Townville, 644.

[23] Veron, J.E.N. (2000) Corals of the World. Vol. 1-3, Australian Institute of Marine Science, Townville, 1382.

[24] Department of Marine Park Malaysia (2011) Handbook on the Living Marine Resources of Malaysia Marine Park. Ministry of Natural Resources and Environment, Putrajaya, 123.

[25] Ismail, A. (1995) Rumpai Laut Malaysia. Dewan Bahasa dan Pustaka, Kuala Lumpur, 277 p.

[26] Bros, W.E. and Cowell, B.C. (1987) A Technique for Optimising Sample Size Replication. Journal of Experimental Marine Biology and Ecology, 114, 63-71. http://dx.doi.org/10.1016/0022-0981(87)90140-7

[27] Zar, J.H. (1999) Biostatistical Analysis. Prentice Hall, Upper Saddle River.

[28] Leujak, W. and Ormond, R.F.G. (2007) Comparative Accuracy and Efficiency of Six Coral Community Survey Methods. Journal of Experimental Marine Biology and Ecology, 351, 168-187. http://dx.doi.org/10.1016/j.jembe.2007.06.028

[29] Jokiel, P.L., Rodgers, K.S., Brown, E.K., Kenyon, J.C., Aeby, G., Smith, W.R. and Farrell, F. (2005) Comparison of Methods Used to Estimate Coral Cover in the Hawaiian Islands. Hawai’i Coral Reef Assessment and Monitoring Pro- 
gram (CRAMP), Hawai'i Institute of Marine Biology, Hawai’i, 22.

[30] Pante, E. and Dustan, P. (2012) Getting to the Point: Accuracy of Point Count in Monitoring Ecosystem Change. Journal of Marine Biology, 2012, Article ID: 802875. http://dx.doi.org/10.1155/2012/802875 